\title{
EXPERIMENTAL INVESTIGATION ON DURABILITY PROPERTIES OF CONCRETE ADDED WITH NANO SILICA
}

\author{
R. Prashanth, S. Senthil Selvan* and M. Balasubramanian \\ Department of Civil Engineering, SRM Institute of Science and Technology, \\ Kancheepuram-603203, (Tamilnadu) India \\ *E-mail: senthilselvan.s@ktr.srmuniv.ac.in
}

\begin{abstract}
The study examined the durability properties of concrete added with Nano-silica. Lifeline buildings and other infrastructures have highlighted concrete durability issues. The use of nanoparticles in materials based on cement has been recently attractive because of the unique properties at Nano-level that they are able to achieve. This can be prominently utilized in enhancing the ductility of cement-based composites which are generally brittle, also cracks at the nanoscale could be arrested by incorporating carbon nanotube or carbon nanofiber. Nano-silica has a unique advantage in the potential pozzolanic-reaction with cement hydration products over other nanoparticles. Addition of Nano-silica is known to redefine pore size and distribution which would alter the durability of the concrete. Durability properties were tested by checking how concrete of grade M30, with $2 \%$ by weight of its cementitious materials replaced with Nano-silica, withstands in alkali environment, acidic environment, sulphate environment, and in a water curing in comparison to conventional concrete of M30 grade in respective environments. The Nanofiller effect and the pozzolanic-reaction increased the homogeneity of the microstructure and the porosity, particularly at the Interfacial Transition Zone, which decreased the permeability of deteriorating gases. Durability tests validated the positive effects of Nano-silica added to concrete. The distribution of pore size also showed that Nano-silica refined the large capillary pores, subsequently decreasing the permeability nature of concrete, enhancing its durability. Also, Nano-silica added concrete mix shows increased compression strength, tensile strength, and flexural strength compared to the conventional concrete mix.
\end{abstract}

Keywords: Nanoparticles, Pozzolanic, Durability, Cementitious, Microstructure, Permeability

@) RASĀYAN. All rights reserved

\section{INTRODUCTION}

Concrete is a widely incorporated material used in constructions for its workability, tolerances, and economy. Its durability is affected due to its porous microstructure which is prone to the intake of truculent ions/fluids in a severe environment ${ }^{2}$. To resolve this issue, various additives and admixtures are added to alter the matrix of the concrete and tested. The use of nanoparticles combined with cement-based materials has gained interest recently because they are capable of altering unique properties at the nanoscale level. For example, Nano- $\mathrm{SiO}_{2}, \mathrm{TiO}_{2}, \mathrm{Fe}_{2} \mathrm{O}_{3}, \mathrm{Al}_{2} \mathrm{O}_{3}$ was used in the cement matrix as a Nanofiller, the capillary pores were found to be refined, and there was a decrease in overall porosity ${ }^{2}$. Further Nano-silica has a unique potential advantage of very early age pozzolanic-reaction because of its size of ultrafine particles in the cement hydration process compared to other nanoparticles. Therefore, Nanosilica helps in promoting hydration of cement when added with fly ash or other such pozzolanicmaterials ${ }^{2}$.

\section{Materials and Methods}

\section{EXPERIMENTAL}

The cement of OPC 53 grade was used and the initial setting time of cement was calculated as 50 minutes. The penetration test was carried out on cement found to be 0 to $5 \mathrm{~min}$. The specific gravity of the cement is 3.15. Coarse aggregates are particulates that are more noteworthy than $4.75 \mathrm{~mm}$. The coarse aggregates of size $20 \mathrm{~mm}$ are utilized for the concrete mix. The specific gravity is determined as 2.65. For

Rasayan J. Chem., 12(2), 685-690(2019)

http://dx.doi.org/10.31788/RJC.2019.1225165

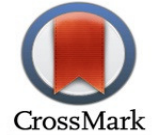


the experiment, river sand passing through a sieve of $4.75 \mathrm{~mm}$ size is used as the fine aggregate. The specific gravity is determined as 2.59. CERAPLAST 300 which is high-grade superplasticizer based on naphthalene, a brown color liquid with nil chloride content having a specific gravity value of $1.2 \pm .03$ is used for the concrete mix at a $2 \%$ of cement content in the mix. Nano-silica with a particle size of ' 17 Nano' and a specific gravity value of 2.2 is used for this experiment. $2 \%$ of the cement content for the NS (Nano-silica added concrete mix) is replaced by Nano-silica.

Sodium sulphate $\mathrm{Na}_{2} \mathrm{SO} \square$, in powder form having $142.04 \mathrm{~g} / \mathrm{mol}$ of molar mass, $2.66 \mathrm{~g} / \mathrm{cm}^{3}$ density which is soluble in water, used for curing in sulphate attack test. Sodium hydroxide $\mathrm{NaOH}$, in crystal form having molar mass $39.99 \mathrm{~g} / \mathrm{mol}$, water-soluble, used for curing in alkali attack test. Hydrochloric acid with the normality of $0.1 \mathrm{~N}$, and with $\mathrm{pH}$ of 1.1 is used for curing in acid attack test.

\section{Concrete Specimens}

CC - Conventional mix. NS- Mix with $2 \%$ weight of cement replaced by Nano-silica. For Nano-silica concrete mix (NS), $2 \%$ by weight of cement in the mix is replaced with Nano-silica. A total of 108 M30 grade concrete specimens were cast for this experiment, in equal numbers of CC and NS, 48 cubes of $150 \mathrm{~mm}$ side, 48 cylinders of $150 \mathrm{~mm}$ diameter and $300 \mathrm{~mm}$ height, and 12 beams $100 \mathrm{~mm}$ square cross section of 500mm length were cast. For the Nano-silica added concrete mix, the Nano-silica is first mixed and added to the mix with water and the superplasticizer.

\section{Curing}

Four types of curing for the concrete specimens done for this experiment. The chemical solutions for different types of curing process are made by mixing the water with suitable chemicals. $0.5 \mathrm{ml} \mathrm{of} \mathrm{HCl}$ (Hydrochloric) acid with 6 liters of water per specimen is the chemical solution mixture used for acid attack test in which the concrete cubes and cylinders are immersed. $426 \mathrm{gms}$ of $\mathrm{Na}_{2} \mathrm{SO}_{4}$ (Sodium Sulphate) with 6 liters of water per specimen is the chemical solution mixture used for sulphate attack test in which the concrete cubes and cylinders are immersed. 24gms of $\mathrm{NaOH}$ (Sodium Hydroxide) with 6 litres of water per specimen is the chemical solution mixture used for sulphate attack test in which the concrete cubes and cylinders are immersed. The fourth type of curing is the standard curing, in which the concrete cubes, cylinders, and beams are immersed in water. Till the day of testing, the concrete specimens are left in curing.

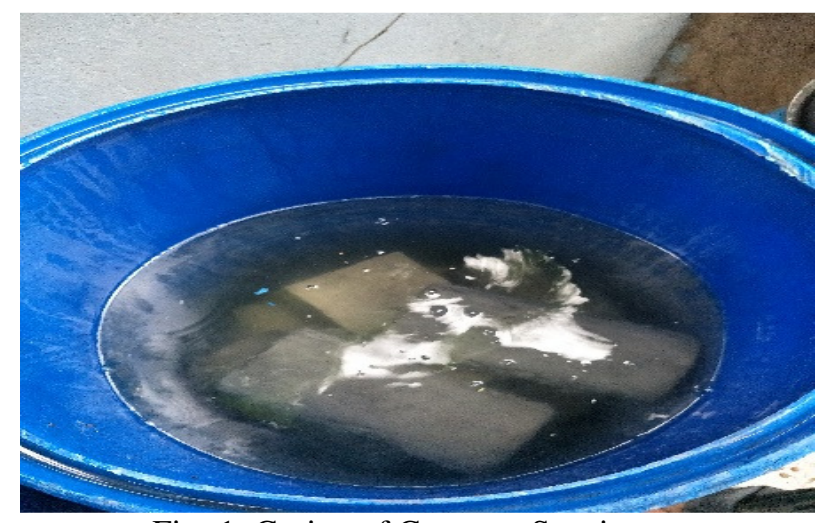

Fig.-1: Curing of Concrete Specimens

\section{RESULTS AND DISCUSSION}

Compressive strengths at 14 and 28 days were determined for the cubes subjected to 4 different types of curing. Similarly, split tensile strengths at 14 and 28 days were determined for the cylinders subjected to 4 different types of curing. Also, flexure strength was determined at 14 and 28 days was determined for the beams. An average of three trials was taken as the result of the following tests carried out.

\section{Compressive Strength}

The compressive strengths of M30 grade concrete cube specimens with and without Nano-silica subjected to normal curing, acid attack, sulphate attack, and alkali attack are tested using compression testing machine. 
Table-1: Compression Strength Test Results of M30 Grade Concrete Cubes

\begin{tabular}{c|c|c|c|c}
\hline \multicolumn{5}{|c}{ M30 Grade Compression Test Results $\left(\mathrm{N} / \mathrm{mm}^{2}\right)$} \\
\hline Curing & \multicolumn{2}{|c|}{ 14 Day Test } & \multicolumn{2}{c}{ 28 Day Test } \\
\hline Mix & CC & NS & CC & NS \\
\hline Water & 23.22 & 28.17 & 33.18 & 40.52 \\
\hline $\mathrm{NaOH}$ & 23.48 & 27.99 & 34.54 & 41.54 \\
\hline $\mathrm{Na}_{2} \mathrm{SO}_{4}$ & 23.95 & 28.78 & 34.72 & 41.42 \\
\hline Acid & 24.57 & 29.96 & 35.10 & 41.61 \\
\hline
\end{tabular}

- The compression test on the CC cubes yielded a 14day strength, cured in water, found to be23.22 $\mathrm{N} / \mathrm{mm}^{2}$, whereas the NS had $28.17 \mathrm{~N} / \mathrm{mm}^{2}$ value. This is a $21.32 \%$ increase.

- The compression test on the CC cubes yielded a 14day strength, cured in alkali environment for alkali attack test, found to be $23.48 \mathrm{~N} / \mathrm{mm}^{2}$, whereas the NS had $27.99 \mathrm{~N} / \mathrm{mm}^{2}$ value. This is a $19.21 \%$ increase.

- The compression test on the CC cubes yielded a 14day strength, cured in sulphate environment for sulphate attack test, found to be $23.95 \mathrm{~N} / \mathrm{mm}^{2}$, whereas the NS had $28.78 \mathrm{~N} / \mathrm{mm}^{2}$ value. This is a $20.17 \%$ increase.

- The compression test on the CC cubes yielded a 14day strength, cured in an acidic environment for acid attack test, found to be $24.57 \mathrm{~N} / \mathrm{mm}^{2}$, whereas the NS had $29.96 \mathrm{~N} / \mathrm{mm}^{2}$ value. This is a $21.96 \%$ increase.

- The compression test on the CC cubes yielded a 28day strength, cured in water, found to be33.18 $\mathrm{N} / \mathrm{mm}^{2}$, whereas the NS had $40.52 \mathrm{~N} / \mathrm{mm}^{2}$ value. This is a $22.14 \%$ increase.

- The compression test on the CC cubes yielded a 28day strength, cured in alkali environment for alkali attack test, found to be $34.54 \mathrm{~N} / \mathrm{mm}^{2}$, whereas the NS had $41.54 \mathrm{~N} / \mathrm{mm}^{2}$. This is a $20.28 \%$ increase.

- The compression test on the CC cubes yielded a 28day strength, cured in sulphate environment for sulphate attack test, found to be $34.72 \mathrm{~N} / \mathrm{mm}^{2}$, whereas the NS had $41.42 \mathrm{~N} / \mathrm{mm}^{2}$. This is a $19.32 \%$ increase.

- The compression test on the CC cubes yielded a 28day strength, cured in an acidic environment for acid attack test, found to be $35.10 \mathrm{~N} / \mathrm{mm}^{2}$, whereas the NS had $41.61 \mathrm{~N} / \mathrm{mm}^{2}$. This is an $18.56 \%$ increase.

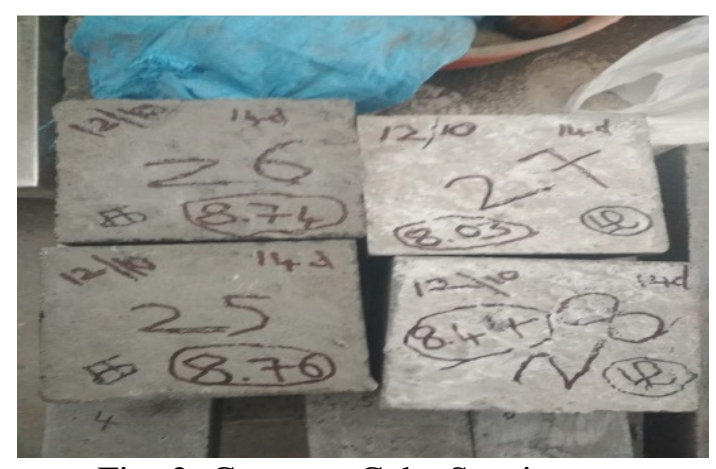

Fig.-2: Concrete Cube Specimens

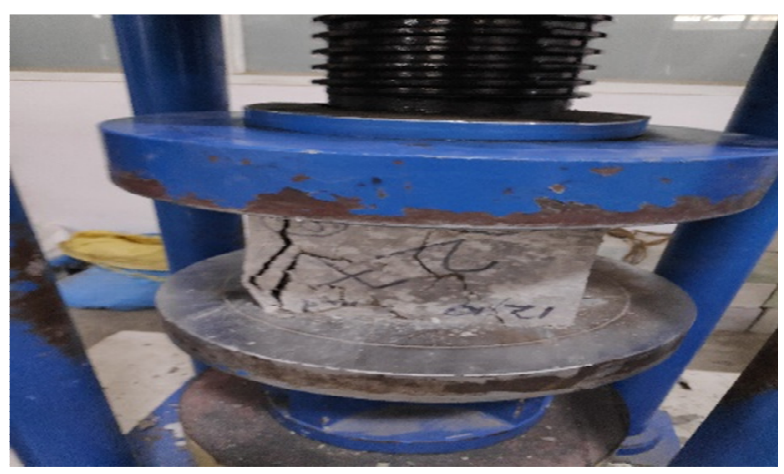

Fig.-3: Compression Test on Concrete Cubes

It is obvious that the addition of Nano-silica to the concrete mix, increases its compressive strength regardless of the testing age. This mechanism happens because of pozzolanic-activity and Nano-filler effect. The refinement of the pore structure of cement paste is carried out due to partial filling of capillary pores and the big voids.

\section{Split-tensile Strength}

M30 grade concrete cylinders cast with and without Nano-silica cured in water, acidic environment, sulphate environment, and alkali environment subjected to split tensile strength test using compression testing machine. 
Table-2: Split Tensile Strength Test Results of M30 Grade Concrete Cylinders

\begin{tabular}{l|l|l|l|l}
\hline \multicolumn{5}{c}{ M30 Grade Split Tensile Test Results } \\
$\left(\mathrm{N} / \mathrm{mm}^{2}\right)$ \\
\hline Curing & \multicolumn{1}{c}{14 Day Test } & \multicolumn{2}{|c}{28 Day Test } \\
\hline Mix & CC & NS & CC & NS \\
\hline Water & 2.37 & 2.53 & 2.46 & 2.96 \\
\hline $\mathrm{NaOH}$ & 2.20 & 2.67 & 2.80 & 3.07 \\
\hline $\mathrm{Na}_{2} \mathrm{SO}_{4}$ & 2.39 & 2.80 & 2.92 & 3.17 \\
\hline Acid & 2.69 & 3.02 & 3.01 & 3.11 \\
\hline
\end{tabular}

- The split tensile strength of the CC cylinders at 14 days cured in water is found to be $2.37 \mathrm{~N} / \mathrm{mm}^{2}$, whereas the NS had $2.53 \mathrm{~N} / \mathrm{mm}^{2}$ value. This is a $6.9 \%$ increase.

- The split tensile strength of the CC cylinders at 14 days cured in alkali environment for alkali attack testis found to be $2.20 \mathrm{~N} / \mathrm{mm}^{2}$, whereas the NS had $2.67 \mathrm{~N} / \mathrm{mm}^{2}$ value. This is a $21.7 \%$ increase.

- The split tensile strength of the CC cylinders at 14 days cured in sulphate environment for sulphate attack testis found to be $2.39 \mathrm{~N} / \mathrm{mm}^{2}$, whereas the NS had $2.80 \mathrm{~N} / \mathrm{mm}^{2}$ value. This is a $17.3 \%$ increase.

- The split tensile strength of the CC cylinders at 14 days cured in an acidic environment for acid attack testis found to be $2.69 \mathrm{~N} / \mathrm{mm}^{2}$, whereas the NS had $3.02 \mathrm{~N} / \mathrm{mm}^{2}$ value. This is a $12.37 \%$ increase.

- The split tensile strength of the CC cylinders at 28 days cured in water is found to be $2.46 \mathrm{~N} / \mathrm{mm}^{2}$, whereas the NS had $2.96 \mathrm{~N} / \mathrm{mm}^{2}$ value. This is a $20.38 \%$ increase.

- The split tensile strength of the CC cylinders at 28 days cured in alkali environment for alkali attack test is found to be $2.80 \mathrm{~N} / \mathrm{mm}^{2}$, whereas the NS had $3.07 \mathrm{~N} / \mathrm{mm}^{2}$ value. This is a $9.96 \%$ increase.

- The split tensile strength of the CC cylinders at 28 days cured in sulphate environment for sulphate attack testis found to be $2.92 \mathrm{~N} / \mathrm{mm}^{2}$, whereas the NS had $3.17 \mathrm{~N} / \mathrm{mm}^{2}$ value. This is an $8.75 \%$ increase.

- The split tensile strength of the CC cylinders at 28 days cured in an acidic environment for acid attack test is found to be $3.01 \mathrm{~N} / \mathrm{mm}^{2}$, whereas the NS had $3.11 \mathrm{~N} / \mathrm{mm}^{2}$ value. This is a $3.52 \%$ increase.

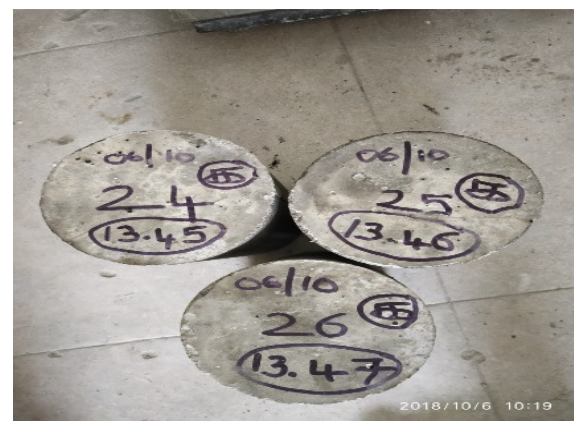

Fig.-4: Concrete Cylinder Specimens

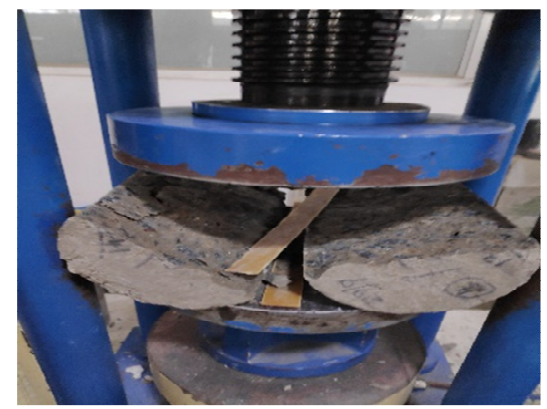

Fig.-5: Split Tensile Strength Test on Concrete Cylinder

It is obvious that, the addition of Nano-silica to the concrete mix, increases its tensile strength regardless of the testing age.

\section{Flexure Strength}

M30 grade concrete beams cast with and without Nano-silica cured in water subjected to flexure strength test using compression testing machine with a suitable arrangement.

- The flexural strength of the CC beams at 14 days cured in water is found to be $4.15 \mathrm{~N} / \mathrm{mm}^{2}$, whereas the NS had $5.30 \mathrm{~N} / \mathrm{mm}^{2}$ value. This is a $27.82 \%$ increase.

- The flexural strength of the CC beams at 14 days cured in water is found to be $4.75 \mathrm{~N} / \mathrm{mm}^{2}$, whereas the NS had $6.02 \mathrm{~N} / \mathrm{mm}^{2}$ value. This is a $26.92 \%$ increase. 
Table-3: Flexure Strength Test Results of M30 Grade Concrete Beams

\begin{tabular}{|c|c|c|c|c|}
\hline \multicolumn{5}{|c|}{$\begin{array}{l}\text { M30 Grade Flexure Test Results } \\
\qquad\left(\mathrm{N} / \mathrm{mm}^{2}\right)\end{array}$} \\
\hline Curing & $14 \mathrm{D}$ & $y$ Test & & \\
\hline Mix & $\mathrm{CC}$ & NS & $\mathrm{CC}$ & NS \\
\hline Water & 4.15 & 5.30 & 4.75 & 6.02 \\
\hline
\end{tabular}

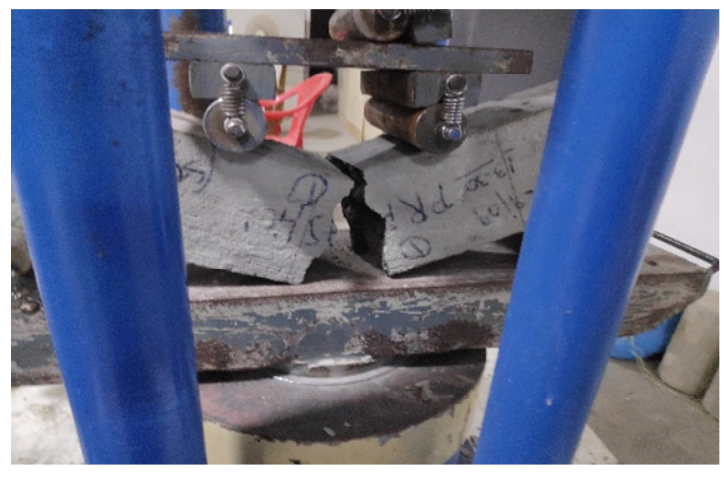

Fig.-6: Concrete Beams

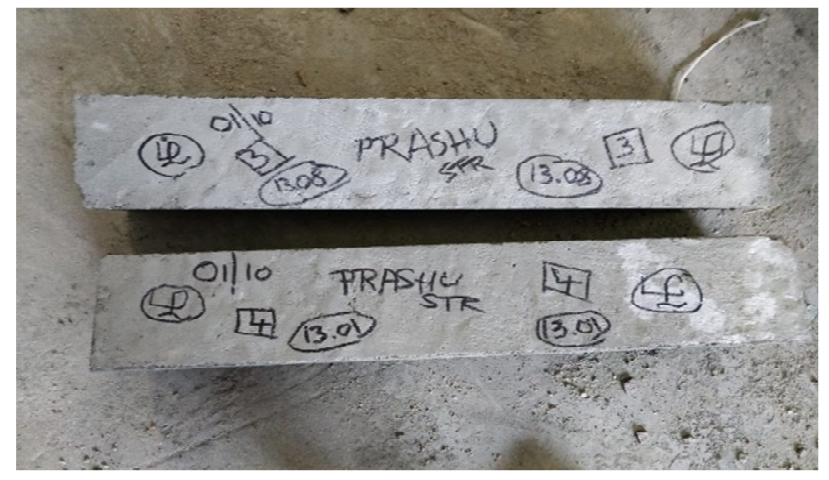

Fig.-7: Flexure Strength Test on the Concrete Beam

It is obvious that, the addition of Nano-silica to the concrete mix, increases its flexural strength regardless of the testing age.

\section{CONCLUSION}

- The inference from the test results in is an increase of $21.73 \%$ compressive strength and increased tensile strength of $13.64 \%$ for M30 grade NS in comparison with same grade CC cured in water.

- The inference from the test results is an increase of $20.26 \%$ compressive strength and increased tensile strength of $8 \%$ for M30 grade NS in comparison with same grade CC cured in the acidic environment using concentrated $\mathrm{HCl}$ (Hydrochloric acid) solution for acid attack test.

- The inference from the test results is an increase of $19.74 \%$ compressive strength and increased tensile strength of $16 \%$ for M30 grade NS in comparison with same grade CC cured in alkali environment using $\mathrm{NaOH}$ (Sodium Hydroxide) solution for alkali attack test.

- The inference from the test results is an increase of $19.7 \%$ compressive strength and increased tensile strength of 13\% for M30 grade NS in comparison with same grade CC cured in sulphate environment using $\mathrm{Na}_{2} \mathrm{SO}_{4}$ (Sodium Sulphate) solution for sulphate attack test.

- The inference from the test results is increased the flexural strength of $27.37 \%$ for M30 grade NS in comparison with same grade CC cured in water.

- Therefore, the addition of Nano-silica to the concrete mix has been shown to lead to an increase in compressive strength, tensile strength, flexural strength, and durability with respect to conventional concrete.

\section{REFERENCES}

1. A. M. Said, M.S. Zeidan, M.T. Bassuoni, Y. Tian, Construction and Building Materials,36, 838(2012), DOI: 10.1016/j.conbuildmat.2012.06.044

2. Hongjian Du, Suhuan Du, Xuemei Liu, Construction and Building Materials, 73, 705 (2014), DOI: 10.1016/j.conbuildmat.2014.10.014

3. R. Yu, P. Spiesz, H.J.H. Brouwers, Construction and Building Materials, 65, 140(2014), DOI: 10.1016/j.conbuildmat.2014.04.063

4. R. BaniArdalan, N. Jamshidi, H. Arabameri, A. Joshaghanid, M. Mehrinejade, P. Sharafi, Construction and Building Materials, 146, 128 (2017), DOI: 10.1016/j.conbuildmat.2017.04.078 
RASĀYAN J. Chem.

Vol. 12 | No. 2 |685 - 690| April - June | 2019

5. P.Vasanthi, S.Senthilselvan, D.BenitaHexton, Mohamed Salman Farooq.I, P.Suresh, International Journal of ChemTech Research, 10(3),693(2017).

6. Hamid Eskandari-Naddaf, Ali Ziaei-Nia,Procedia Manufacturing,22, 399 (2018), DOI: 10.1016/j.promfg.2018.03.062

7. Mohammad Balapour,AlirezaJoshaghani, FadiAlthoey, Construction and Building Materials, 181, 27 (2018), DOI: 10.1016/j.conbuildmat.2018.05.266

8. K. Rajkumar, Prem Ranjan, P. Thavamani, P. Jeyanthi, P. Pazhanisamy, Rasayan J. Chem.,6(2), 122 (2013).

9. L. Krishnaraj, Yeddula Bharath Simha Reddy, N. Madhusudhan, P.T. Ravichandran, Rasayan J. Chem.,10(2), 423 (2017), DOI: 10.7324/RJC.2017.1021682

10. Kushal Ghosh, Partha Ghosh, Rasayan J. Chem., 11(1), 426(2018), DOI: 10.7324/RJC.2018.1112036

[RJC-5165/2019] 